\title{
INSILIO: FORMAS Y SIGNIFICADOS CONTEMPORÁNEOS DEL EXILIO
}

\author{
MIGUEL TUDELA-FOURNET \\ Universidad Autónoma de Madrid
}

\begin{abstract}
RESUMEN: A través del estudio de la institución del exilio, de las distintas significaciones y concepciones que a lo largo de los tiempos varias tradiciones de pensamiento político le han conferido, este trabajo propone rescatar el significado del exilio, como categoría conceptual, resignificándolo como insilio, para explicar una serie de procesos sociales y políticos, con implicaciones tanto individuales como colectivas, de nuestra contemporaneidad.
\end{abstract}

PALABRAS CLAVE: exilio; insilio; pensamiento grecolatino; postmodernidad.

\section{Insile: contemporary forms and meanings of exile}

ABSTRACT: Through the study of the institution of exile, the different meanings and perceptions over time different traditions of political thought have given it, this work proposes to recover the meaning of exile, as a conceptual category, as «insile», to explain a number of social and political processes, with both individual and collective implications, of our contemporaneity.

KEY WORDS: exile; insile; ancient greek and latin thought; postmodernity.

El hombre es un ser simultáneamente solitario y social. En tanto que ser solitario, trata de proteger su propia existencia y la de aquellos que le rodean, satisfacer sus necesidades personales y desarrollar sus aptitudes innatas. Como ser social, procura merecer el reconocimiento y afecto de sus semejantes, compartir sus alegrías, confortarlos cuando sufren y mejorar sus condiciones generales de vida. Sólo la existencia de estos diversos impulsos, con frecuencia conflictivos entre sí, explica el carácter propio de un hombre. ${ }^{1}$

En esa relación dialéctica se ha ido configurando la intrahistoria humana. Al individuo se le ha concebido tan pronto miembro insustituible y único, irrepetible, ajeno y aislado de la comunidad, cuya individualidad debe prevalecer sobre cualquier identidad grupal, como tan pronto una voz anónima pero sumativa que se debe adherir inevitablemente al conjunto, cuya identidad particular es intrascendente para el grupo y cuya importancia radica tan sólo en la pertenencia a éste, como la importancia de cada uno de los instrumentos de una orquestra que interpretan una sinfonía, donde cada uno, tomado por sí mismo, no es más que una pequeña pieza inútil e incapaz de armonizar todas las notas, mientras que, en conjunto, cobra sentido y participa de la construcción de la melodía, del tempo, del ritmo, del acompañamiento... En esta línea, ya Aristóteles se preguntaba «¿Por qué la misma persona con la misma voz se hace oír más lejos cantando o gritando con otros que si lo hace él solo?», respondiéndose que «cuando hay gente reunida, la fuerza de la voz se unifica

1 Einstein, A., El socialismo y el futuro de la humanidad, Hacer Editorial, Barcelona, 2005, p. 19. 
y empuja el aire al mismo tiempo, de modo que lo proyecta multiplicado: pues la voz que procede de todos es mucho mayor que la voz que procede de cada una por separado» ${ }^{2}$.

Es esta una dicotomía que, en la historia del pensamiento, llega hasta nuestros días. El propio Isaiah Berlin desarrolla sobre estas bases sus dos sentidos de la libertad, "sentidos que son, sin embargo, fundamentales; que tienen a sus espaldas gran cantidad de historia humana y, me atrevería a decir, la van a seguir teniendo $»^{3}$.

Independientemente de cómo consideremos al individuo, a la sociedad y sus interacciones, lo cierto es que un instrumento al que nunca ha renunciado el poder político es el del exilio, el de expulsar de la comunidad a aquel individuo que, por una causa u otra, sobresale en el conjunto. Un instrumento que, si bien formalmente ha desaparecido de nuestros ordenamientos jurídicos occidentales de corte liberal y democrático-representativo, no lo ha hecho sustantivamente, como defenderemos a lo largo de este trabajo.

Ver cuál ha sido la evolución del exilio, cómo se ha conceptualizado, cuáles eran los sentimientos que generaba, repasar hasta qué punto podía suponer un castigo o una recompensa (en cualquier caso, siempre una distinción), vinculándola con nuestra contemporaneidad, con las teorías defendidas por la Escuela de Frankfurt y por el paradigma postmoderno es el objetivo de este ensayo.

\section{EL EXILIO: ORIGEN E INTERPRETACIÓN}

Maquiavelo, en sus Discursos sobre la primera década de Tito Livio, aborda, aunque muy tangencialmente, el tema del exilio, tema, por lo demás, alejado de su principal centro de interés. Dicha mención la hace al referirse a la Constitución de los atenienses, atribuida a Aristóteles, donde se afirma que "Clístenes dio otras nuevas [leyes] para hacerse con el pueblo, entre las que estableció el ostracismo» ${ }^{4}$. En concreto, Maquiavelo explica su origen, las razones de su institución como herramienta política, vinculándola a la gratitud o ingratitud de los pueblos republicanos.

Quien lea los sucesos de las repúblicas, encontrará que en todas hubo algún tipo de ingratitud para con los ciudadanos, pero encontrará menos ejemplos de ello en Roma que en Atenas o en cualquier otra república. Y buscando la causa de esto, y refiriéndome a Roma y Atenas, pienso que sucedía porque los romanos tenían menos motivos para sospechar de sus ciudadanos que los atenienses. Porque Roma, considerando el período que va desde la expulsión de los reyes hasta Sila y Mario, nunca fue privada de la libertad por alguno de

2 Aristóteles, Problemas, Gredos, Madrid, 2004, p. 255.

3 Berlin, I., Dos conceptos de libertad y otros escritos, Alianza, Madrid, 2008, p. 47.

4 Aristóteles, Constitución de los atenienses, Gredos, Madrid, 1984, p. 102. 
sus ciudadanos, de modo que no tenía causa importante para sospechar de ellos y, en consecuencia, ofenderlos sin consideración. Sucedió muy al contrario en Atenas, pues habiéndole arrebatado la libertad Pisístrato, en su época más florida, y engañándola con apariencia de bondad, cuando al fin volvió a ser libre, acordándose de las injurias recibidas y de la pasada servidumbre, se convirtió en diligente vengadora, no ya de los errores, sino de la sombra de los errores de sus ciudadanos. De aquí nació el exilio y la muerte de tantos hombres excelentísimos, de aquí la institución del ostracismo, y todas las demás violencias que contra sus mejores hombres cometió la ciudad en diversos tiempos. $^{5}$

No es azaroso que el exilio naciera en la Grecia clásica, en el seno de las poleis, donde y cuando nuestra concepción de lo político encuentra su raíz.

Sin entrar a discutir con Maquiavelo sobre si fueron más o menos numerosos los exiliados de una república o de otra, lo cierto es que, incluso en el supuesto de que fueran menos en Roma, eso no significa que fueran menos relevantes, como se precisará en lo que sigue. Pero antes cabe preguntarse cómo era interpretado el exilio entre los griegos de la época clásica.

«El ostracismo podía parecer a los griegos como un destino peor que la muerte ${ }^{6}$. Siempre sesgados por una tradición de pensamiento que se ha alineado con la defensa de la inocencia de Sócrates, "porque los que la han difundido han sido todos filósofos ${ }^{7}$, sin prestar nunca ninguna atención a las razones que pudieron motivar su condena, el exilio ha sido generalmente interpretado como uno de los más duros castigos que se puede infligir a una persona, a un ciudadano. Expulsarle de la polis, de su ciudad, de su medio, de su contexto, equivalía a condenarlo no sólo a la soledad, sino a un estado de naturaleza brutal y animal que ya Aristóteles señalaba, cuando afirmaba:

(...) que la ciudad es una de las cosas naturales, y que el hombre es por naturaleza un animal social, y que el insocial por naturaleza y no por azar o es mal hombre o más que hombre, como aquel a quien Homero increpa: «sin tribu, sin ley, sin hogar», porque el que es tal por naturaleza es además amante de la guerra. ${ }^{8}$

Para la tradición de pensamiento occidental, o al menos para una gran parte de ella, el ser humano es tal en tanto en cuanto está en contacto con sus semejantes. Por eso, «el conocimiento mayor y el más bello es, con mucho, la regulación de lo que concierne a las ciudades ${ }^{9}$. También por eso, cuando habla del destierro, Séneca lo describe en estos términos:

5 Maquiavelo, N., Discursos sobre la primera década de Tito Livio, Alianza, Madrid, 2008, pp. 106-107.

6 Barber, B., Strong Democracy, University of California Press, Berkeley, 1984, p. 69. Traducción del autor.

7 Ibid., p. 96

8 Aristóteles, Política, 1253a, 5-7.

9 Platón, El banquete, 209a. 
La más difícil de las cuestiones que he planteado parece ser la que he dicho primero, esto es, que son provechosos a quienes les ocurren esos hechos que nos horrorizan y hacen temblar. - ¿Les es provechoso-, dices, - ser arrojados al destierro, ser arrastrados a la necesidad, enterrar a los hijos, a la esposa, sufrir una deshonra, padecer una mutilación? ${ }^{10}$

Esa interpretación del exilio es la que lleva a Sócrates a preferir la cicuta a la huida; prefiere, «habiéndome defendido así, morir que, de aquel otro modo, vivir» ${ }^{11}$.

Benjamin Barber, señalando este sesgo de la historia del pensamiento, pero sin renunciar a un posicionamiento acorde al mismo, traza, en su ya clásico Strong democracy, una breve evolución de la conceptualización del sentimiento del exilio. En ella muestra cómo, por arte de birlibirloque, lo que tradicionalmente ha sido tan temido, tan denostado, se ha resignificado, cargándose de valores positivos, deseables, a través de la alquimia del pensamiento liberal.

Ha sido el genio de liberalismo el que ha transformado lo inevitable en deseable, el destino peor que la muerte en la vida ideal, y las paredes invisibles que nos separan del jardín en baluartes que nos protegen de las tentadoras intimidades comunales. No hay redención, sólo el paraíso de la soledad. En este nuevo y sofisticado nirvana, la lucha por superar y trascender el aislamiento es suplantada por la lucha encaminada a fortificarlo con derechos y para apuntalarlo con la libertad y el poder. La comunión viene a significar interferencia; el exilio se convierte en intimidad. ${ }^{12}$

Si bien Barber acierta cuando señala a Hobbes y a Descartes como los primeros grandes filósofos que empiezan a darle contenido teórico consistente a esta interpretación de la vida societal y del individuo, en cuya estela se situarán los liberales como Locke o Bastiat, omite que en la tradición literaria ya existían, de muy antiguo, posiciones contrapuestas que interpretaban, cada una a su manera, el exilio. Estas formas son las que encarnan, por un lado, Plutarco y, por otro, Ovidio.

Plutarco (ca. 50-ca. 125), el autor de Vidas paralelas, en Sobre el exilio trata de enfrentarse a toda la tradición que interpretaba dolorosamente la ruptura de los lazos que unían al ciudadano con la polis. Haciendo balance del exilio, dice:

De ahí que, quedándonos a solas con nosotros mismos, pasemos a evaluar, como si fuesen fardos, el peso de cada uno de los contratiempos. Pues el cuerpo es presionado por el peso del cuerpo, pero el alma muchas veces aporta desde sí misma peso a las cosas. La piedra es dura por naturaleza, el hielo frío por naturaleza, y no es desde fuera ni por azar como nos comunican esas cualidades de resistencia y congelación. Ahora bien, sucesos como el destierro, la mala reputación y la privación de honores, como a su vez los contrarios —distinciones, cargos y privilegios—, al no tener como patrón de

10 SÉnECA, Sobre la providencia, III, 2.

11 Platón, Apología de Sócrates, $38 \mathrm{e}$.

12 Barber, B., op. cit., p. 69. 
dolor y de bienestar su propia naturaleza sino nuestro criterio, cada cual los juzga para sí ligeros o pesados, fáciles de soportar o lo contrario. ${ }^{13}$

Sin entrar a sondear el planteamiento sobre la construcción subjetiva de la realidad que late en estas líneas, Plutarco abre la puerta a nuevas interpretaciones del sentimiento del exilio, unas interpretaciones que relativizan su importancia y que lo van connotando, no forzosamente de sentidos positivos, pero sí de la posibilidad de resignificarlo. Una resignificación que, en el diagnóstico que hace Plutarco, se ve imposibilitada por la estrechez de miras con las que lo concebimos. "Al dirigir nuestra atención a un solo aspecto del exilio - la pérdida de reputación-, pasamos por alto el reposo, el ocio y la libertad que proporciona» ${ }^{14}$, una pérdida de reputación que pone más adelante en solfa, afirmando que es «ridículo pensar que al exilio va aparejada la mala reputación» ${ }^{15}$.

Así, desde la perspectiva de Plutarco, el exilio no es ni mucho menos una condena, sino, muy al contrario, casi un regalo, porque, contemplando «la verdad despojada de vana opinión, el que tiene una sola ciudad es un extranjero y un extraño en todas las demás » ${ }^{16}$; en cualquier caso, una distinción. Pareciera, en consecuencia, que se adelantara en varios siglos a una perspectiva sobre el ostracismo y la soledad que, como bien defiende Barber, encontrará su apogeo teorético en el liberalismo.

Tal vez la vehemencia de Plutarco en defensa de esa concepción del exilio sea una respuesta a las Tristes y a las Pónticas de Ovidio (43 a.C-17 d.C), las cartas y las elegías que, desde la ciudad de Tomis, el autor del Ars amandi compuso en su exilio. En ellas encuentra ese desgarramiento, ese extrañamiento que sufre el ser humano cuando se le arranca de entre los suyos, de su contexto, una de sus mejores y más bellas expresiones. La melancolía, la desazón, la desesperación cobran entidad en sus palabras.

El color que tienen en otoño las hojas batidas por los primeros fríos, a las que dañó el nuevo invierno, es el mismo que tienen mis miembros; no me siento aliviado con ningún remedio y nunca me falta motivo para quejarme a causa del dolor. Ni ando mejor del espíritu que del cuerpo, sino que ambos se hallan enfermos por igual y padezco un doble sufrimiento. Fija está y cual cuerpo que se puede contemplar se yergue ante mis ojos la imagen visible de mi fortuna; y cuando veo el lugar, las costumbres de sus habitantes, su porte exterior y su lengua y me viene el recuerdo de quién soy y quién fui, se apodera de mí un deseo tan fuerte de morir que me quejo de la ira del César por no vengar sus ofensas con la espada. ${ }^{17}$

Ovidio confiesa en estas líneas que él también hubiera preferido beber la cicuta. No encuentra ningún sentido a su existencia, siente que el ser humano

\footnotetext{
13 Plutarco, Sobre el exilio, 599D.

14 Ibid., 604C.

15 Ibid., 605D.

16 Ibid., 602B.

17 Ovidio, Tristes, Libro III, 8, 30-40.
} 
no puede ser tal si no está en su comunidad. Su desesperación se agudiza según van pasando los días, los meses, los años. «He aquí que en vano (pues, ¿de qué me ha servido haber nacido?) se acerca la fecha de mi cumpleaños. Cruel, ¿por qué venías a añadirte a los desgraciados años de un exiliado? ${ }^{18}$.

Los días se le van convirtiendo en tragos amargos, cuya única escapatoria es la rutina, el trabajo sin sentido (pues no hay finalidad alguna en él).

Aquí, aunque las armas de los pueblos vecinos resuenan a mi alrededor, trato de aliviar como puedo mi triste destino con la poesía, y aunque no hay aquí nadie a cuyos oídos pueda recitársela, sin embargo, de este modo voy pasando y engañando el tiempo. ${ }^{19}$

\section{LA RESIGNIFICACIÓN DEL EXILIO Y SUS IMPLICACIONES PARA LA VIDA POLÍTICA}

La resignificación del exilio, de la soledad humana, que «ha sido a menudo visto como una aberración, una patología o una maldición $»^{20}$ y que Benjamin Barber atribuye al espíritu liberal, ha generado una sociedad en donde «las posibilidades de tener comunidad se reducen, y la esperanza de tener una democracia que pueda ser tan comunitaria como igualitaria y tan participativa como consensuada se marchitan $»^{21}$. Una sociedad compuesta por individuos que están aislados unos de otros.

El moderno cliente-consumidor privado que reclama sus derechos, vende sus servicios, contrata sus relaciones, vota sus intereses y hace un análisis de coste-beneficio de su plan de vida es un hombre que no existe para los demás. $^{22}$

El «otro» se erige, a la manera hobbesiana, en competidor, en rival, en una amenaza para cada uno de nosotros.

De modo que, en la naturaleza del hombre, encontramos tres causas principales de disensión. La primera es la competencia; en segundo lugar, la desconfianza; y en tercer lugar, la gloria. ${ }^{23}$

Pero el liberalismo no es sólo responsable de la resignificación de la soledad humana o del exilio. Paralela, causa y consecuencia a la vez, a esta construcción teórica, el liberalismo ha ido diseñando, a partir de unas premisas determinadas, toda una cosmovisión que, si en su base encuentra el hombre "que existe sólo para sí mismo, sin tener en cuenta al resto de la especie, a la justicia, a la necesidad, a la igualdad o a la obligación es un Hombre Solo in

18 Ibid., Libro III, 13, 5.

19 Ibid., Libro IV, 9, 110-115.

20 Barber, B., op. cit., p. 69.

21 Ibid., p. 70.

22 Ibid., p. 71.

23 Hobbes, T., Leviatán, Alianza, Madrid, 1993, p. 107. 
extremis $»^{24}$, en su centro se encuentra el pensamiento económico, y en el centro de éste, la propiedad.

El que se alimenta de las bellotas que recoge debajo de una encina, o de las bayas silvestres que arranca a los árboles del bosque, ciertamente que se las ha apropiado para él mismo. Nadie podrá poner en duda su derecho a alimentarse de ellas. Ante lo cual, me pregunto si empezaron a ser suyas cuando las digirió, cuando las engulló, cuando las cogió, cuando las llevó a casa, o cuando las escogió. Y es evidente que si no fue la recolección lo que las convirtió en suyas, en tal caso nada más pudo hacerlo. Fue precisamente ese trabajo lo que las distinguió de lo que es común, pues les añadió algo que no había sido hecho por la naturaleza, la madre común de todas las cosas, y así, pasaron a ser un derecho privado suyo. ${ }^{25}$

La combinación de estos factores fue desarrollando todo un sistema económico que encontró en la racionalidad más absoluta su lógica de funcionamiento y en la alteración de medios y fines su resignificación simbólica, su trasvase de sacralidad, una resignificación y un trasvase que ha permitido que lo que se constreñía a la esfera económica de la vida social haya trascendido sus límites, impregnando con su lógica racional el resto de las esferas de la vida.

[La llamada a hacer dinero] era para muchos una vocación religiosa -la obediencia a la voluntad de Dios-, pero, a medida en que el mundo occidental se secularizaba progresivamente a causa en gran medida de la extensión del mismo capitalismo moderno, su estatuto vocacional también comenzó a secularizarse y a atenuarse. Aunque nunca desapareció, este fenómeno pasó a un segundo plano y a convertirse realmente en innecesario como factor de motivación para el hombre de negocios. ${ }^{26}$

Individuos aislados en la sociedad, con una sola y misma lógica de comportamiento, atrapados en una " jaula de hierro", en la que "los bienes materiales han llegado a obtener (...) un poder inexorable sobre las vidas de los hombres" ${ }^{27}$ y cuyo único objetivo es consumir, en un mercado en el que hasta «la "cultura" se ha vuelto un producto por derecho propio» ${ }^{28}$.

Esta interpretación del liberalismo y del individuo es una constante del pensamiento contemporáneo. Žižek, aunque con intención de oponerse a toda esa unanimidad que existe en el mundo intelectual, parafraseando a Marx, lo expone con tono irreverente cuando dice que «Un espectro ronda la academia universal, el espectro del sujeto cartesiano. Todos los poderes académicos han entrado en una santa alianza para exorcizarlo» ${ }^{29}$. Sirva también esta cita para subrayar la filiación cartesiana del liberalismo, ya que la filiación hobbesiana ya había sido expuesta unas líneas más arriba.

\footnotetext{
24 BARBER, B., op. cit., p. 71.

25 Locke, J., Segundo ensayo sobre el gobierno civil, capítulo V, 28.

26 Lessnoff, M., La filosofía política del siglo XX, Akal, Madrid, 2011, p. 26.

27 Ibid., 29

28 Jameson, F., Teoría de la posmodernidad, Editorial Trotta, Madrid, 1996, p. 10

29 ŽıžeK, S., El espinoso sujeto, Paidós, Buenos Aires, 2001, p. 9
} 
Aunque con diferencias de acento, diversos pensadores contemporáneos coinciden en esa soledad del individuo. Lyotard lo expresa claramente cuando dice que «cada uno se ve remitido a sí mismo. Y cada uno sabe que ese sí mismo es poco»" ${ }^{30}$, que apreciamos una «disolución del lazo social y el paso de las colectividades sociales al estado de una masa compuesta de átomos individuales $»^{31}$.

Mongardini recurre a las palabras de Hannah Arendt y de Horkheimer para explicar qué está ocurriéndole al individuo en nuestros días:

De la soledad protorromántica de los comienzos de la modernidad que contraponía soledad a sociedad hemos pasado a la soledad entre la muchedumbre de la modernidad tardía: una soledad en la sociedad, en la que el aislamiento y la superficialidad, como escribe Arendt, «son evidentemente síntomas de la sociedad de masas, aunque su significado auténtico no se agote en ella». En efecto, Arendt afirma también que cuando se habla de «sociedad atomizada» o de «individuos aislados» debemos entender «aquella condición en la que los individuos viven juntos sin tener nada en común, sin compartir una parte tangible y visible del mundo» (...) De nada valen los exorcismos; nuestra era de comunicación es también la de mayor soledad. «Todos nos quedamos solos —escribe Horkheimer-; las máquinas pueden trabajar y hacer cálculos pero son incapaces de tener ideas o de introducirse en la piel del otro. A pesar de la actividad, los hombres se hacen más pasivos; a pesar de su poder, crece la impotencia de cara a la sociedad y a ellos mismos ${ }^{32}$

Por analogía, podemos decir que estas nuevas coordenadas son el Ponto Euxino al que fue enviado Ovidio, y que el aislamiento de cada uno de los individuos, en tanto que tal, y en tanto que se le considera como tal, es el mismo lamento del poeta, que se ve obligado a renunciar a parte de sí mismo.

Yo mismo, famoso poeta romano (iperdonadme, Musas!), me veo obligado a hablar la mayor parte de las cosas en la lengua de los sármatas. He aquí (me avergüenza, lo confieso) que, por el largo desuso, apenas si a mí me salen ya palabras latinas. ${ }^{33}$

La gran diferencia entre un aislamiento y otro es que uno era un hecho notorio y el otro es un hecho sutil y, por eso, más eficaz, como denuncia Marcuse en El hombre unidimensional. «La libre elección de amos no suprime ni a los amos ni a los esclavos» ${ }^{34}$, dirá plásticamente.

\footnotetext{
30 LyotaRd, F., La condición postmoderna, Cátedra, Madrid, 1989, p. 39

31 Ibid., 29

32 Mongardini, C., Miedo y sociedad, Alianza, Madrid, 2007, pp. 98-99

33 Ovidio, Tristes, Libro V, 7, 55.

34 Marcuse, H., El hombre unidimensional, Seix Barral, Barcelona, 1972, p. 38.
} 


\section{EXILIO E INSILIO}

En el caso de los exilios de Ovidio, de Plutarco, de los prohombres griegos, existía un desplazamiento físico real. Miles de kilómetros de distancia entre el punto de origen y el punto de destino, un paisaje diferente, incluso lenguas distintas, hacían que el exiliado recordara su condición a cada momento. Un exilio que, por lo demás, estaba a la orden del día, contemplado por todas las disposiciones legales.

Pero esa formalidad ha desaparecido de nuestros sistemas políticos. Y si bien parece que hace mucho tiempo que ha desaparecido, si echamos la vista atrás nos encontramos con que el exilio ha estado muy presente en una generación de intelectuales cuya vida ha transcurrido a lo largo del siglo XX. El tema (o al menos temas que le son muy cercanos) aparece en diversos escritos. Hannah Arendt habla de la condición del apátrida en términos muy parecidos a los de Ovidio o a los de la conceptualización de la vida política griega.

La primera pérdida que sufrieron los privados de derechos fue la de sus hogares; esto significaba la pérdida de todo el entramado social en el que habían nacido y en el que habían establecido para sí mismos un lugar diferenciado en el mundo. ${ }^{35}$

Tan presente puede llegar a ser que Vintila Horia recupera la figura y el exilio de Ovidio en una de sus novelas.

Dieu est né en exil. Journal d'Ovide à Tomes se configura como una escritura sensible en la que se intuyen ciertos rasgos de carácter autobiográfico de las vivencias del destierro del propio autor, producido veinte siglos más tarde que el de Ovidio, una escritura evocadora de sentimientos, una escritura de la vivencia del exilio que la convierte en universal, más allá de las delimitaciones geográficas o cronológicas que la inscriben. ${ }^{36}$

Evidentemente, este tipo de exilio contemporáneo al que nos referimos no puede ser, en consecuencia, idéntico al exilio del pasado. No existe, en nuestro caso, un desplazamiento físico, un cambio de coordenadas espaciales de ningún tipo. Pero acierta Tudoras subrayando la universalidad del sentimiento del exilio. Siendo diferentes por la existencia o no de un desplazamiento, una forma en que podemos redefinirlo es atribuyéndole un nuevo significante. Y éste, siendo «exilio» una palabra de origen latino compuesta por el prefijo «ex» (fuera) y por el verbo «sălǐo» (saltar) ${ }^{37}$, puede ser el «insilio», palabra, por lo demás, que también existe en latín y cuyo significado es «saltar sobre». Sin

35 Arendt, H., Los orígenes del totalitarismo, Alianza, Madrid, 2006, p. 416.

36 Tudoras, L. E., «La narrativa francófona del siglo XX: un escenario para la memoria del exilio». En Kahl, T., KReuter, P. M. y Vogel, C. (eds.), Vergessen, verdrängt, verschwunden. Aufgegebene Kulturen, Beziehungen und Orientierungen in der Balkanromania, Frank \& Timme, Berlin, 2018, p. 238. La cursiva es nuestra.

37 Segura, S., Nuevo diccionario etimológico Latín-Español y de las voces derivadas, Universidad de Deusto, Bilbao, 2006, p. 271. 
atender al significado del verbo, pero sí al del prefijo, nuestra propuesta, habida cuenta del desarrollo etimológico del término «exilio», parece que puede tener cierta solidez semántico-lingüística ${ }^{38}$.

La única diferencia, pues, del exilio y del insilio sería su desplazamiento físico, quedando sustantivamente definido por las mismas sensaciones y los mismos sentimientos, esas sensaciones y esos sentimientos que Weber, Marcuse, Arendt, Horkheimer, Lyotard, Barber, Mongardini, Tudoras ${ }^{39}$, Jameson,... detectan en el sujeto y en el contexto contemporáneo. Un aislamiento que viene reforzado por «la angustiada expectativa de que nada habrá de ocurrir, de que el capitalismo continuará indefinidamente ${ }^{40}$ y contra el que Negri se opone cuando señala que "hacer multitud es hacer democracia» ${ }^{41}$.

El insilio, pues, viene caracterizado no sólo por la soledad del ser humano, una soledad que se erige en la piedra angular de nuestra organización social y de nuestra cosmovisión, sino también por la capacidad de ese sistema de engullir y digerir hasta las alternativas al mismo que se ofrecen, integrándolas en su lógica mercantil. "La postmodernidad es el consumo de la pura mercantilización como proceso ${ }^{42}$.

Un sistema que, además, ha ahogado en libertad la propia libertad.

Los derechos y libertades que fueron factores vitales en los orígenes y etapas tempranas de la sociedad industrial se debilitan en una etapa más alta de esta sociedad (...). La libertad de pensamiento, de palabra y de conciencia eran (...) esencialmente ideas críticas, destinadas a reemplazar una cultura material e intelectual anticuada por otra más productiva y racional. Una vez institucionalizados, estos derechos y libertades compartieron el destino de la sociedad en la que se habían convertido en parte integrante. La realización anula las premisas. ${ }^{43}$

Pero sus implicaciones para el sujeto contemporáneo son más profundas. Si bien el exilio siempre ha sido interpretado como un castigo, abriera o no nuevas puertas, comportara o no una pérdida de reputación, la mera existencia de la posibilidad del exilio situaba unos límites, conocidos por todos, que no se podían franquear. Y el pensamiento, igual que el arte, tantea los límites morales y éticos de su época.

38 Asimismo, es de reseñar que «insilio» viene siendo ya utilizado, al menos, por la crítica literaria, como lo ilustra, entre otros, el artículo de Ingeschay, D., «Exilio, insilio y diáspora. La literatura cubana en la época de las literaturas sin residencia fija», en Ángulo Recto. Revista de estudios sobre la ciudad como espacio plural, vol. 2, núm. 1, 2010. Consultado el 20/04/2016 en https://revistas.ucm.es/index.php/ANRE/article/viewFile/ANRE1010120004A/6101

${ }_{39}$ Véase Tudoras, L. E., La configuración de la imagen de la gran ciudad en la literatura postmoderna (ámbito románico), Universidad Complutense de Madrid, Madrid, 2006.

${ }_{40}$ ŽIžEK, S., La suspensión política de la ética, Fondo de Cultura Económica, Buenos Aires, 2005, p. 189.

41 Negri, A., La fábrica de porcelana. Una nueva gramática de la politica, Paidós, Barcelona, 2008, p. 214.

42 JAMESON, F., op. cit., p. 10.

43 Marcuse, H., op. cit., p. 31. La cursiva es nuestra. 
Subsiste una cierta constancia en la posición moral e intelectual de todo verdadero artista: para realizar su trabajo el artista se acerca, inevitablemente, a algún límite de la experiencia humana, a una zona oscura o borrosa en su novedad, difícil de nombrar, y ante la cual la cultura de su época no cuenta con instrumentos establecidos o consensuados con los que poder describirla. A esta tarea está llamado el artista: a nombrar. ${ }^{44}$

Al desaparecer esos límites, el límite de lo decible y de lo indecible, la alteridad, que es el proceso por el que se construye la identidad, desaparece con ellos. El pensador, el artista, queda atrapado por la propia libertad de decir lo que quiera, amparándose en la libertad de expresión, sin que eso signifique ningún tipo de desafío o de provocación ética y moral a su contemporaneidad. Sus coordenadas vitales, intelectuales y existenciales, que siempre se construyen a partir de un punto de referencia determinado, se desvanecen, habida cuenta de que ese punto de referencia se disuelve. Porque el exilio, como límite de lo permitido y lo no permitido, suponía, en el fondo, una distinción, la misma distinción que reclamaba Sócrates en su defensa cuando afirma que "si me condenáis a muerte, no fácilmente encontraréis a otro semejante» ${ }^{45}$. El exilio significaba haber sido capaz de franquear esos límites ahora desaparecidos. Y no cabe pensar que esa desaparición sea casual.

Weber demuestra lúcidamente cómo la esclavitud desaparece racionalmente del sistema económico.

Hacer uso del trabajo libre es más racional, razona, porque —inter aliala adquisición de esclavos requiere una inversión de capital más abundante y arriesgada que la del empleo del trabajo libre (que puede ser siempre permitir la posibilidad de despido, y el pago de salarios darse por terminado); es más probable que el trabajador empleado sea más bueno en su trabajo porque "parte de la selección conforme a las aptitudes se entrega a los propios trabajadores» (...); por otra parte, a los esclavos, a diferencia de los trabajadores empleados, no se les pueden con toda seguridad ofrecer tareas que impliquen un alto nivel de responsabilidad (puede que los trabajadores libremente empleados deseen conservar sus trabajos, mientras que puede que los esclavos tengan tan escaso interés en realizar esto que a menudo lo que buscan es tratar de escapar). El trabajo libre es, por lo tanto, «formalmente» más racional, no en el sentido de que ofrezca grandes posibilidades para el cálculo numérico de los costes y beneficios económicos, sino más bien en la medida en que un empresario racional pretende lograr un máximo de beneficio y, realizando los cálculos pertinentes, prefiere emplear a través del trabajo libre. ${ }^{46}$

Por analogía, el exilio, podemos pensar, no ha desaparecido azarosamente de nuestros sistemas políticos. Bien al contrario, cabe pensar que la desaparición de la institución del ostracismo ha estado sujeta a un escrupuloso cálculo del coste y del beneficio, comportando, a su vez, la aparición del insilio, un exilio

\footnotetext{
44 Sanmartín, R., Meninas, espejos e hilanderas, Editorial Trotta, Madrid, 2005, p. 16.

45 Platón, Apología de Sócrates, 30e.

46 Lessnof, M., op. cit., p. 27.
} 
colectivo que atenaza la libertad individual de los miembros de la comunidad, que acalla las voces críticas permitiéndoles hablar, pero usurpándoles un público que pueda escucharles, inculcando la certeza de que, pase lo que pase, como decía Žižek, nada va a ocurrir, que el sistema triunfante va a continuar permanentemente con nosotros, que la condena a la existencia del «hombre que no existe para los demás» ${ }^{47}$ es para siempre. Un exilio que nos aísla de nuestros semejantes, rompiendo los lazos sociales que hacen la multitud, una multitud informada y con sentido.

Pero no todo está perdido. Tanto la experiencia histórica, como la politología y la sociología, nos enseñan que las grandes organizaciones sociales engendran en su seno las vías que acabarán con ellas mismas ${ }^{48}$. Al mismo tiempo que las calzadas romanas permitieron la rápida movilización de falanges por todo el imperio, esas mismas calzadas permitieron la circulación de ideas que cuestionaban el poder de Roma. Del mismo modo que la modernidad y la postmodernidad nos condenan al insilio, a la atomización del individuo en la sociedad, ese individuo "no está aislado, está atrapado en un cañamazo de relaciones más complejas y más móviles que nunca. Joven o viejo, hombre o mujer, rico o pobre, siempre está situado sobre "nudos" de circuitos de comunicación, por ínfimos que éstos sean» ${ }^{49}$.

\section{ConcLusión}

En este trabajo hemos intentado aportar una nueva definición de «eso que nos está pasando» y que el pensamiento moderno y postmoderno trata de definir y de averiguar, de nombrar y de aprehender, desde lo zweckrational y lo wertrational weberiano hasta la propuesta postmoderna lyotardiana pasando por la unidimensionalidad de Marcuse y los postulados de la Escuela de Frankfurt, por las reflexiones de Arendt y de Mongardini. Una definición que trata de aunar, conscientes de la discontinuidad que existe entre el mundo antiguo y el mundo contemporáneo, a partir del cambio cuantitativo y cualitativo que en todas las esferas de la vida social supuso la Revolución Industrial, la Ilustración y el proyecto de la modernidad, lo antiguo y lo contemporáneo. Y esa unión pasa por una experiencia vital que, independientemente de cómo se denomine o de cuáles sean sus coordenadas espaciales y temporales, independientemente de que se interprete a la manera liberal o a la manera comunitarista, en su esencia se parecen mucho: el exilio y el insilio. Una experiencia cuyas implicaciones socio-políticas, a título individual, conocemos bien gracias a la práctica sistemática que desde todos los regímenes políticos se ha venido haciendo desde los tiempos de la Atenas del siglo de Pericles, pero que, a título colectivo,

\footnotetext{
47 BARBER, B., op. cit., p. 71

48 Véase Mann, T., Las fuentes del poder social, I, Alianza, Madrid, 1991.

49 LyOTARD, F., op. cit., p. 37.
} 
tan sólo podemos intuir y sobre las que sólo podemos intentar arrojar un poco de luz en nuestra contemporaneidad.

\section{BibliografíA}

Arendt, H. (2006). Los orígenes del totalitarismo. Madrid: Alianza. Aristóteles (1951). Política. Madrid: Instituto de Estudios Políticos. Aristóteles (1984). Constitución de los atenienses. Madrid: Gredos. Aristóteles (2004). Problemas. Madrid: Gredos.

Barber, B. (1984). Strong democracy. Berkeley: University of California Press.

Berlin, I. (2008). Dos conceptos de libertad y otros escritos. Madrid: Alianza.

Einstein, A. (2005). El socialismo y el futuro de la humanidad. Barcelona: Hacer Editorial. Hobbes, T. (1993). Leviatán. Madrid: Alianza.

Jameson, F. (1996). Teoría de la posmodernidad. Madrid: Trotta,.

Lessnoff, M. (2011). La filosofía política del siglo XX. Madrid: Akal.

Locke, J. (1991). Dos ensayos sobre el gobierno civil. Madrid: Espasa Calpe.

Lyotard, F. (1989). La condición postmoderna. Madrid: Cátedra.

Maquiavelo, N. (2008). Discursos sobre la primera década de Tito Livio. Madrid: Alianza. Mann, M. (1991). Las fuentes del poder social, I. Madrid: Alianza.

Marcuse, H. (1972). El hombre unidimensional. Barcelona: Seix Barral.

Mongardini, C. (2007). Miedo y sociedad. Madrid: Alianza.

Negri, A. (2008). La fábrica de porcelana. Barcelona: Paidós.

Ovidio (1992). Tristes. Pónticas. Madrid: Gredos.

Platón (2002)-Apología de Sócrates. Fedón. Madrid: Consejo Superior de Investigaciones Científicas.

Platón (1986). Diálogos III. Fedón. Banquete. Fedro. Madrid: Gredos.

Plutarco (2009). Consejos políticos. Sobre el exilio. Madrid: Alianza.

Sanmartín, R. (2005). Meninas, espejos e hilanderas. Madrid: Trotta.

Segura, S. (2006). Nuevo diccionario etimológico Latín-Español y de las voces derivadas. Bilbao: Universidad de Deusto.

Séneca, L. A. (2000). Diálogos. Madrid: Gredos.

Tudoras, L. E. (2006). La configuración de la imagen de la gran ciudad en la literatura postmoderna (ámbito románico). Madrid: Universidad Complutense de Madrid.

Tudoras, L. E. (2018). «La narrativa francófona del siglo XX: un escenario para la memoria del exilio». En Kahl, T., Kreuter, P. M.; Vogel, C. (eds.), Vergessen, verdrängt, verschwunden. Aufgegebene Kulturen, Beziehungen und Orientierungen in der Balkanromania. Berlín: Frank \& Timme, 237-250.

Žižek, S. (2001). El espinoso sujeto. Buenos Aires: Paidós.

Žižek, S. (2005). La suspensión política de la ética. Buenos Aires: Fondo de Cultura Económica.

Universidad Autónoma de Madrid

Miguel Tudela-Fournet

migueltudela@gmail.com

[Artículo aprobado en diciembre de 2016] 